\title{
A Novel Approach to Solve Power Flow for Islanded Microgrids Using Modified Newton Raphson with Droop Control of DG
}

\author{
Faisal Mumtaz, Student Member, IEEE, M. H. Syed, Student Member, IEEE, \\ Mohamed Al Hosani, Member, IEEE, and H. H. Zeineldin, Senior Member, IEEE
}

\begin{abstract}
The study of power flow analysis for microgrids has gained importance where several methods have been proposed to solve these problems. However, these schemes are complicated and not easy to implement due to the absence of a slack bus as well as the dependence of the power on frequency as a result of the droop characteristics. This paper proposes simple and effective modifications to the conventional method (Newton Raphson) to compute the power flow for microgrids. The presented method provides a simple, easy to implement, and accurate approach to solve the power flow equations for microgrids. The proposed method is applied to two test systems: a 6-bus system and a 38-bus system. The results are compared against simulation results from PSCAD/EMTDC which validate the effectiveness of the developed method. The proposed technique can be easily integrated in current commercially available power system software and can be applied for power system studies.
\end{abstract}

Index Terms-Distributed generation (DG), islanded microgrid, power flow.

\section{INTRODUCTION}

$\mathbf{P}$ OWER flow studies have been an active topic for research since early 1960's. They play an important role in the planning and the design of future expansion of the power system. In addition, power flow studies are essential to optimize the operation of existing power systems [1], [2]. The welldeveloped power flow methods using Gauss, Gauss-Seidel, Newton-Raphson and their decoupled versions are presented in [3].

Deregulation in power system has elevated the interest in DG. With the increasing penetration of DG, they can satisfy the needs of local loads alone. These independent DGs make small networks called microgrids. Microgrids operate either in grid connected or islanded modes. In grid connected mode, the voltage and frequency of the system are maintained by the main grid, whereas in islanded mode they are not constant.

This work was supported by the Masdar Institute, PO Box 54224, Abu Dhabi, UAE.

Faisal Mumtaz is with the College of Science and Engineering, Hamad Bin Khalifa University, P.O. Box 5825, Doha, Qatar. (e-mail: faimumtaz@hbku.edu.qa).

M. H. Syed is with the Institute for Energy and Environment, Electronics and Electrical Engineering Department, University of Strathclyde, G1 1XQ, Glasgow, UK (e-mail: mazheruddin.syed@strath.ac.uk).

H. H. Zeineldin and M. Al Hosani are with the Department of Electrical Engineering and Computer Science, Masdar Institute, P.O. Box 54224, Abu Dhabi, UAE (e-mail: hzainaldin@masdar.ac.ae; mohalhosani@masdar.ac.ae). H. H. Zeineldin is currently on leave from the Faculty of Engineering, Cairo University, Giza, 12316, Egypt.
Literature suggests that the power flow for an islanded microgrid cannot be solved using conventional approaches, hence the conventional method like Newton Raphson (which is most widely used in power system studies) cannot be applied to islanded microgrids. Conventional load flow algorithms are valid when slack bus is present and system frequency is constant i.e. grid connected mode [4]-[7]. Now, since the system frequency is not constant in an islanded microgrid, the $Y_{b u s}$ is also not constant because the reactance in the $Y_{b u s}$ depends on the frequency. Also, the conventional assumption to classify the droop bus (the bus at which the DG is connected) either as slack, PV or PQ bus in a power flow is invalid as the active and reactive powers as well as the voltage magnitude and angle of the droop bus are not pre-specified and depend upon the system parameters so conventional methods are not applicable in case of an islanded microgrid [8]-[10]. Thus, new methods have been proposed to solve the power flow analysis for islanded microgrids [5]-[7]. These methods take into account the droop characteristics of DGs. A new power flow formulation that incorporates the droop bus has been presented as a set of nonlinear equations and solved using a globally convergent Newton-trust region method in [5]. In [7], the algorithm was modified by introducing a virtual impedance in the droop model. In [6], a novel load flow technique that utilizes particle-swarm is proposed for islanded microgrids. The proposed methods are accurate but are complex and not easy to implement and extend for power system studies. Furthermore, these papers suggest that the conventional methods cannot be applied to islanded microgrids. In [11] and [12], power flow for an islanded microgrid is solved using the conventional approach in which the DG with highest rating is selected as the slack bus while other DGs are represented as PV or PQ buses. The method considers the frequency in an islanded microgrid to be constant. Other power flow methods, such as backward/forward sweep (BFS) method, proposed in [13]-[16] are specifically designed for distribution systems. However, the applications of BFS method and its variants are only limited to radial and weakly meshed distribution systems [13]-[15].

This paper proposes a novel approach to solve the power flow for islanded microgrids using a Modified Newton Raphson (MNR), and taking into account the droop characteristics of DGs. Three different droop approaches have been incorporated and implemented on two test systems. To validate the effectiveness of the proposed power flow algorithms, 
the results are compared against simulation results from PSCAD/EMTDC.

The organization of this paper is as follows: Load model, $Y_{\text {bus }}$ model and DG model are presented in Section II. In Section III, the problem formulation and the proposed power flow method are presented. Validation results are provided in Section IV to show the effectiveness and accuracy of the proposed method. Conclusions are drawn in Section V.

\section{SySTEM MODELS}

The models of the system are an important factor influencing the power flow study of microgrids. In the following subsections, the load, $Y_{\text {bus }}$ and DG models are presented.

\section{A. Load Model}

For a static load model, the power relationship to voltage and frequency is an exponential equation. A static load model can be represented as [5], [17]

$$
\begin{gathered}
P_{L k}=P_{L_{k o}}\left(\frac{\left|V_{k}\right|}{\left|V_{o}\right|}\right)^{\alpha}\left(1+K_{p f}\left(\omega-\omega_{o}\right)\right), \\
Q_{L_{k}}=Q_{L_{k_{o}}}\left(\frac{\left|V_{k}\right|}{\left|V_{o}\right|}\right)^{\beta}\left(1+K_{q f}\left(\omega-\omega_{o}\right)\right),
\end{gathered}
$$

where $\left|V_{o}\right|$ and $\omega_{o}$ are the nominal voltage magnitude and frequency, respectively; $\left|V_{k}\right|$ is the voltage magnitude of bus $k ; \omega$ is the system frequency; $P_{L k_{o}}$ and $Q_{L k_{o}}$ are the active and reactive power of bus $k$ corresponding to the nominal operating voltage, respectively; $\alpha$ and $\beta$ are the active and reactive power exponents, respectively. The exponent values for different types of loads can be found in [17] and [18]. $(\omega-$ $\left.\omega_{o}\right)$ is the deviation in the angular frequency. $K_{p f}$ and $K_{q f}$ are the frequency sensitivity parameters of the load model. $K_{p f}$ ranges from 0 to 3 and $K_{q f}$ ranges from -2 to 0 depending on the load type, geographical regions, and seasons [17], [19].

\section{B. Ybus Model}

For an $N$ bus system, $Y_{b u s}$ is defined as a matrix representing the nodal admittance of all buses in a system. In case of droop based control of DGs in an islanded microgrid, the system frequency cannot be treated as a fixed parameter. Since the system frequency affects the line reactance, it should be taken into account for the $Y_{b u s}$ calculation. Therefore, for a system with $N$ buses, $Y_{\text {bus }}$ will be a function of the system frequency as follows

$$
Y_{\text {bus }}(\omega)=\left[\begin{array}{ccc}
Y_{11}(\omega) & \ldots & Y_{1 N}(\omega) \\
\vdots & \ddots & \vdots \\
Y_{N 1}(\omega) & \ldots & Y_{N N}(\omega)
\end{array}\right]
$$

where

$$
Y_{k n}(\omega)= \begin{cases}-Z_{k n}^{-1}(\omega) & \forall k \neq n \\ \sum_{\substack{k=1 \\ k \neq n}}^{N} Z_{k n}^{-1}(\omega) & \forall k=n\end{cases}
$$

and $Z_{k n}=R_{k n}+j X_{k n}$ is the per unit impedance between bus $k$ and $n$.

\section{Distributed Generation Model}

The majority of the DGs in an islanded microgrid have a power inverter interface followed by a filter. Therefore, it is justified to assume the output impedance of the DG to be inductive [20]-[22]. Hence, in the droop mode of operation, the active and reactive power sharing of DGs depends on the droop characteristics of DGs which can be represented as follows [23], [24]

$$
\begin{gathered}
\omega=\omega_{o}-m_{p}\left(P_{G}-P_{o}\right), \\
|V|=\left|V_{o}\right|-n_{q}\left(Q_{G}-Q_{o}\right),
\end{gathered}
$$

where $P_{G}$ and $Q_{G}$ are the active and reactive power of the DG, respectively; $m_{p}$ and $n_{q}$ are the frequency and voltage droop coefficients, respectively; $P_{o}$ and $Q_{o}$ are the active and reactive power set points, respectively; and are normally set to zero [25]. For DGs with resistive output impedance, the droop equations exchange their role and can be expressed as [26], [27]

$$
\begin{gathered}
\omega=\omega_{o}+m_{p}\left(Q_{G}-Q_{o}\right), \\
|V|=\left|V_{o}\right|-n_{q}\left(P_{G}-P_{o}\right) .
\end{gathered}
$$

In this paper, conventional droop equations ((5) and (6)) based on an inductive output impedance are considered in accordance with the IEEE standard 1547.7 for distributed generation islanded system [28]. This assumption is valid because of the coupling inductor connected at the output of the converter [23], [24]. However, the output impedance of a DG can be resistive because of the absence of the coupling inductor or due to the presence of highly resistive lines in the distribution network. If no assumptions are made, the output impedance of a DG is practically complex, and the active and reactive power generation of the DG are not decoupled. The proposed method is valid even in case of resistive or complex output impedance of DG. To show the robustness and effectiveness of the proposed method, two special cases of resistive and complex output impedance are also considered which are implemented by replacing the conventional droop equations with the resistive and complex droop equations, respectively. In case of complex output impedance, the active and reactive power generation of the DG is affected by both the system frequency and the bus voltage. In such case, the $P-V-\omega$ and $Q-V-\omega$ droops are used which are given by [29], [30]

$$
\begin{gathered}
\omega=\omega_{o}-m_{p}\left(P_{G}-Q_{G}\right), \\
|V|=\left|V_{o}\right|-n_{q}\left(P_{G}+Q_{G}\right) .
\end{gathered}
$$

For the purpose of steady state analysis, the droop based DG unit comprising of the energy resource, power electronic inverter and the output filter is modeled as a controlled voltage source. The energy resource, power inverter, and output filter do not affect the power flow solution [24].

\section{Proposed Power Flow Methods}

Modified Newton Raphson (MNR) is proposed to solve the power flow problem for islanded microgrids using a novel approach in which the droop control of the DG is combined with the conventional Newton Raphson (NR) method. 


\section{A. Defining the Buses in the System}

To solve the power flow of any system, the first step is to identify the types of buses present in that system. The type of a bus depends upon the pre-specified quantities. The welldefined buses for the conventional power flow are: the PQ bus, the PV bus and the slack bus, which are used in the NR method when solving the power flow problem using the conventional approach. In a multi-source islanded microgrid, the assumption of any DG to act as a slack bus is inoperative as there is no single DG capable of maintaining the system frequency and its local bus voltage constant [5]. In this study, we re-classify the bus types for islanded microgrids as follows:

1) PQ bus: The active and reactive power are known.

2) PV bus: The voltage magnitude and active power are known.

3) VF dependent bus: The active and reactive powers of the bus are dependent upon the bus voltage and system frequency.

In order to provide a reference for the voltage angles in the system, a reference bus is chosen. A reference bus can be a $\mathrm{PQ}, \mathrm{PV}$ or VF dependent bus.

\section{B. Problem Formulation}

In the conventional NR method, the slack bus voltage is fixed at $1 \angle 0^{\circ}$ and all the remaining system buses are initialized with a voltage of $1 \angle 0^{\circ}$ which will change with each iteration. The active and reactive power mismatch is calculated and through the Jacobian, the voltage magnitude and angle mismatches are determined. The convergence criterion is based on setting a tolerance on the voltage magnitude and angle mismatch [3]. For a system with $N$ buses, the polar form of the power flow equations is given by [3]:

$$
\begin{aligned}
& P_{c k}=\left|V_{k}\right| \sum_{n=1}^{N}\left|Y_{k n}\right|\left|V_{n}\right| \cos \left(\delta_{k}-\delta_{n}-\theta_{k n}\right), \\
& Q_{c k}=\left|V_{k}\right| \sum_{n=1}^{N}\left|Y_{k n}\right|\left|V_{n}\right| \sin \left(\delta_{k}-\delta_{n}-\theta_{k n}\right),
\end{aligned}
$$

where $P_{c k}$ and $Q_{c k}$ are the calculated real and reactive power supplied to bus $k$, respectively. $\left|V_{k}\right|$ is the voltage magnitude of bus $k$ and $\left|Y_{k n}\right|$ is the magnitude of $Y_{k n} . \delta_{k}$ and $\delta_{n}$ are the voltage angles of buses $k$ and $n$, respectively, while $\theta_{k n}$ is the angle of $Y_{k n}$. Assuming the first bus to be the slack bus, the calculated values of the real power $\left(\boldsymbol{P}_{c}\right)$ and reactive power $\left(\boldsymbol{Q}_{c}\right)$ of the other buses are obtained from (11) and (12), respectively; and are compared with the scheduled values to obtain the mismatch matrix $(\boldsymbol{\Delta})$ as follows.

$$
\boldsymbol{\Delta}=\left[\begin{array}{ll}
\boldsymbol{P}^{T}-\boldsymbol{P}_{c}^{T} & \boldsymbol{Q}^{T}-\boldsymbol{Q}_{c}^{T}
\end{array}\right]^{T},
$$

$\boldsymbol{P}, \boldsymbol{P}_{c}, \boldsymbol{Q}$ and $\boldsymbol{Q}_{c}$ are given in Appendix B. Equations (11) and (12) are then differentiated with respect to the voltage angle and magnitude and the Jacobian matrix is calculated using

$$
\boldsymbol{J}=\left[\begin{array}{ll}
\boldsymbol{J}_{11} & \boldsymbol{J}_{12} \\
\boldsymbol{J}_{21} & \boldsymbol{J}_{22}
\end{array}\right]
$$

where $\boldsymbol{J}_{11}, \boldsymbol{J}_{12}, \boldsymbol{J}_{21}$ and $\boldsymbol{J}_{22}$ are the Jacobian sub-matrices (given in Appendix B). Once the Jacobian matrix is obtained, the voltage angle and magnitude for all buses for the $(i+1)$ iteration can be calculated as

$$
\boldsymbol{x}^{i+1}=\boldsymbol{x}^{i}+\boldsymbol{J}^{-1} \cdot \boldsymbol{\Delta},
$$

where

$$
\boldsymbol{x}=\left[\begin{array}{ll}
\boldsymbol{\delta}^{T} & |\boldsymbol{V}|^{T}
\end{array}\right]^{T},
$$

$\boldsymbol{\delta}$ and $|\boldsymbol{V}|$ are the vectors of voltage angles and magnitudes, respectively of all the buses except bus 1 (assuming bus 1 to be the slack bus).

It is worth mentioning that the conventional NR method can be applied to islanded microgrids operating using the master/slave approach [11], [12]. For the above method to be applicable to an islanded microgrid equipped with the droop approach, certain issues need to be addressed. Firstly, there is no slack bus in an islanded microgrid. Secondly, the droop bus needs to be formulated. Thirdly, the system frequency is not constant. Further, the losses in the system cannot be attributed to the slack bus (as it is not present) and needs to be distributed among the sources in the microgrid. In order to address these issues, this paper proposed a novel approach to solve the power flow using the MNR method.

\section{Modified Newton Raphson (MNR)}

In order to solve for the voltage angle and magnitude of a droop bus at the $(i+1)$ iteration, the active and reactive powers of the droop buses need to be calculated (to be added to the mismatch matrix). Assuming the output impedance of the DG to be inductive, and by setting the references $P_{o}$ and $Q_{o}$ to zero in (5) and (6) [25], the active and reactive powers of the droop bus $k$ can be expressed as

$$
\begin{gathered}
P_{G k}{ }^{i+1}=\frac{1}{m_{p_{k}}}\left(\omega_{o}-\omega^{i}\right), \\
Q_{G_{k}}{ }^{i+1}=\frac{1}{n_{q_{k}}}\left(\left|V_{o}\right|-\left|V_{k}{ }^{i}\right|\right) .
\end{gathered}
$$

If the active and reactive powers of the droop bus violate the limit, the respective power is set to its limit value. As can be observed from (17), the active power of the droop bus is dependent upon the system frequency. The system frequency acts as a mean of communication among all the droop control buses to share the loads in the system. In other words, all the droop buses in the microgrid will supply active power at the same angular frequency, i.e. the system angular frequency. For $d$ number of droop buses in the system, the sum of active powers can be represented as

$$
P_{\text {sys }}=\sum_{k=1}^{d} P_{G k}=\sum_{k=1}^{d} \frac{1}{m_{p_{k}}}\left(\omega_{o}-\omega\right)
$$

Similarly, the sum of reactive powers can be represented as

$$
Q_{s y s}=\sum_{k=1}^{d} Q_{G_{k}}=\sum_{k=1}^{d} \frac{1}{n_{q_{k}}}\left(\left|V_{o}\right|-\left|V_{k}\right|\right)
$$

In case of the MNR power flow method, along with the assumption of bus voltages at the beginning of the power flow, an initial system frequency $(\omega)$ of 1 p.u. is assumed. In addition 
to $\omega$, bus 1 voltage magnitude $\left(\left|V_{1}\right|\right)$ is another variable in the MNR method (because of the absence of the slack bus). The variable vector $\left(\boldsymbol{x}^{\prime}\right)$ is given by

$$
\boldsymbol{x}^{\prime}=\left[\begin{array}{llll}
\boldsymbol{\delta}^{T} & |\boldsymbol{V}|^{T} & \omega & \left|V_{1}\right|
\end{array}\right]^{T}
$$

A flowchart of the MNR method is presented in Fig. 1. The objective is to calculate the modified Jacobian matrix $\left(\boldsymbol{J}^{\prime}\right)$ and the modified mismatch matrix $\left(\boldsymbol{\Delta}^{\prime}\right)$. The modified mismatch matrix is given by

$$
\boldsymbol{\Delta}^{\prime}=\left[\begin{array}{llll}
\boldsymbol{P}^{T}-\boldsymbol{P}_{c}^{T} & \boldsymbol{Q}^{T}-\boldsymbol{Q}_{c}^{T} & P_{t o t}-P_{s y s} & Q_{t o t}-Q_{s y s}
\end{array}\right]^{T}
$$

Four new terms are included in the modified mismatch matrix. $P_{t o t}$ is the sum of the total active power demand and the $P_{l o s s}$. The sum of active powers of the DGs $\left(P_{t o t}\right)$ can be replaced by the total active power demand $\left(P_{\text {load }}\right)$ in the system plus the active power losses $\left(P_{\text {loss }}\right)$ in the system. The total reactive power $\left(Q_{t o t}\right)$ of the system is the sum of the total reactive load $\left(Q_{\text {load }}\right)$ and the reactive power loss $\left(Q_{\text {loss }}\right)$ such that:

$$
\begin{aligned}
P_{\text {tot }} & =P_{\text {load }}+P_{\text {loss }} \\
Q_{\text {tot }} & =Q_{\text {load }}+Q_{\text {loss }}
\end{aligned}
$$

Hence, losses are required to be calculated in each iteration and are calculated using the following equation:

$$
\begin{gathered}
P_{\text {loss }}=\frac{1}{2} \sum_{k=1}^{N} \sum_{n=1}^{N} \Re\left\{Y_{k n}\left(V_{k}^{*} V_{n}+V_{n}^{*} V_{k}\right)\right\} \\
Q_{\text {loss }}=-\frac{1}{2} \sum_{k=1}^{N} \sum_{n=1}^{N} \Im\left\{Y_{k n}\left(V_{k}^{*} V_{n}+V_{n}^{*} V_{k}\right)\right\}
\end{gathered}
$$

Then, the scheduled real powers $(\boldsymbol{P})$, scheduled reactive powers $(\boldsymbol{Q})$, calculated real powers $\left(\boldsymbol{P}_{c}\right)$ and calculated reactive powers $\left(\boldsymbol{Q}_{c}\right)$ are determined for all buses. The objective is to make the mismatch matrix $\left(\boldsymbol{\Delta}^{\prime}\right)$ equal to zero. To obtain the modified Jacobian matrix $\left(\boldsymbol{J}^{\prime}\right)$, equations (11) and (12) are differentiated with respect to $\delta,|\boldsymbol{V}|, \omega$ and $\left|V_{1}\right|$. Additionally, (19) and (20) are also differentiated with respect to $\delta,|\boldsymbol{V}|, \omega$ and $\left|V_{1}\right|$ to determine the complete modified Jacobian matrix. The modified Jacobian matrix is given by

$$
\boldsymbol{J}^{\prime}=\left[\begin{array}{cc:cc}
\boldsymbol{J} & \boldsymbol{J}_{13}^{\prime} & \boldsymbol{J}_{14}^{\prime} \\
\hdashline \boldsymbol{J}_{31}^{\prime} & \overline{\boldsymbol{J}}_{32}^{\prime} & \boldsymbol{J}_{33}^{\prime} & \boldsymbol{J}_{34}^{\prime} \\
\boldsymbol{J}_{41}^{\prime} & \boldsymbol{J}_{42}^{\prime} & \boldsymbol{J}_{43}^{\prime} & \boldsymbol{J}_{44}^{\prime}
\end{array}\right]
$$

The first sub-matrix of the modified Jacobian is the same as the Jacobian of the regular Newton Raphson method and can be calculated using (14). The remaining 12 sub-matrices are the modified Jacobian sub-matrices for the MNR method and

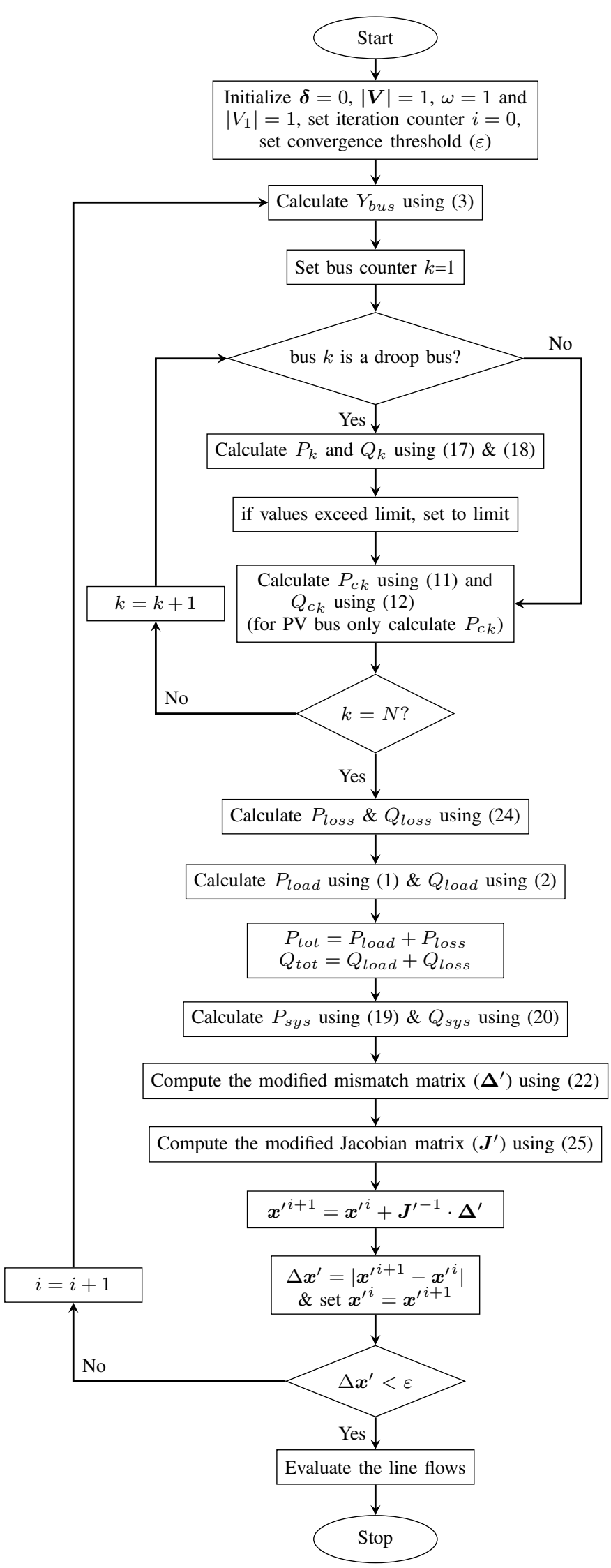

Fig. 1. Flowchart of the proposed MNR method 
are calculated using

$$
\begin{aligned}
\boldsymbol{J}_{41}^{\prime} & =\left[\begin{array}{lll}
\frac{\partial Q_{s y s}}{\partial \delta_{2}} & \ldots & \frac{\partial Q_{s y s}}{\partial \delta_{N}}
\end{array}\right], \boldsymbol{J}_{42}^{\prime}=\left[\begin{array}{lll}
\frac{\partial Q_{s y s}}{\partial\left|V_{2}\right|} & \ldots & \frac{\partial Q_{s y s}}{\partial\left|V_{N}\right|}
\end{array}\right] \\
\boldsymbol{J}_{31}^{\prime} & =\left[\begin{array}{lll}
\frac{\partial P_{s y s}}{\partial \delta_{2}} & \ldots & \frac{\partial P_{s y s}}{\partial \delta_{N}}
\end{array}\right], \boldsymbol{J}_{32}^{\prime}=\left[\begin{array}{lll}
\frac{\partial P_{s y s}}{\partial\left|V_{2}\right|} & \ldots & \frac{\partial P_{s y s}}{\partial\left|V_{N}\right|}
\end{array}\right] \\
\boldsymbol{J}_{43}^{\prime} & =\left[\begin{array}{lll}
\frac{\partial Q_{s y s}}{\partial \omega}
\end{array}\right], \boldsymbol{J}_{23}^{\prime}=\left[\begin{array}{lll}
\frac{\partial Q_{c_{2}}}{\partial \omega} & \ldots & \frac{\partial Q_{c_{N}}}{\partial \omega}
\end{array}\right]^{T}, \\
\boldsymbol{J}_{44}^{\prime} & =\left[\begin{array}{lll}
\frac{\partial Q_{s y s}}{\partial\left|V_{1}\right|}
\end{array}\right], \boldsymbol{J}_{24}^{\prime}=\left[\begin{array}{lll}
\frac{\partial Q_{c 2}}{\partial\left|V_{1}\right|} & \ldots & \frac{\partial Q_{c_{N}}}{\partial\left|V_{1}\right|}
\end{array}\right]^{T}, \\
\boldsymbol{J}_{33}^{\prime} & =\left[\begin{array}{lll}
\frac{\partial P_{s y s}}{\partial \omega}
\end{array}\right], \boldsymbol{J}_{13}^{\prime}=\left[\begin{array}{lll}
\frac{\partial P_{c 2}}{\partial \omega} & \ldots & \frac{\partial P_{c N}}{\partial \omega}
\end{array}\right]^{T} \\
\boldsymbol{J}_{34}^{\prime} & =\left[\begin{array}{lll}
\frac{\partial P_{s y s}}{\partial\left|V_{1}\right|}
\end{array}\right], \boldsymbol{J}_{14}^{\prime}=\left[\begin{array}{lll}
\frac{\partial P_{c 2}}{\partial\left|V_{1}\right|} & \ldots & \frac{\partial P_{c N}}{\partial\left|V_{1}\right|}
\end{array}\right]^{T}
\end{aligned}
$$

Detailed expressions of the partial terms in the modified Jacobian sub-matrices are as follows:

$$
\begin{aligned}
\frac{\partial P_{c k}}{\partial \omega}= & \left|V_{k}\right| \sum_{n=1}^{N}\left[\frac{\partial\left|Y_{k n}\right|}{\partial \omega}\left|V_{n}\right| \cos \left(\delta_{k}-\delta_{n}-\theta_{k n}\right)+\right. \\
& \left.\frac{\partial \theta_{k n}}{\partial \omega}\left|Y_{k n}\right|\left|V_{n}\right| \sin \left(\delta_{k}-\delta_{n}-\theta_{k n}\right)\right]
\end{aligned}
$$

where

$$
\begin{gathered}
\frac{\partial\left|Y_{k n}\right|}{\partial \omega}=-\frac{X_{k n}^{2} / \omega}{\left(R_{k n}^{2}+X_{k n}^{2}\right)^{3 / 2}}, \frac{\partial \theta_{k n}}{\partial \omega}=-\frac{X_{k n} /\left(\omega R_{k n}\right)}{1+\left(X_{k n} / R_{k n}\right)^{2}} \\
\frac{\partial Q_{c k}}{\partial \omega}=\left|V_{k}\right| \sum_{n=1}^{N}\left[\frac{\partial\left|Y_{k n}\right|}{\partial \omega}\left|V_{n}\right| \sin \left(\delta_{k}-\delta_{n}-\theta_{k n}\right)-\right. \\
\left.\frac{\partial \theta_{k n}}{\partial \omega}\left|Y_{k n}\right|\left|V_{n}\right| \cos \left(\delta_{k}-\delta_{n}-\theta_{k n}\right)\right] \\
\frac{\partial P_{c k}}{\partial\left|V_{1}\right|}=\left|V_{k}\right|\left|Y_{k 1}\right| \cos \left(\delta_{k}-\delta_{1}-\theta_{k 1}\right) \\
\frac{\partial Q_{c k}}{\partial\left|V_{1}\right|}=\left|V_{k}\right|\left|Y_{k 1}\right| \sin \left(\delta_{k}-\delta_{1}-\theta_{k 1}\right)
\end{gathered}
$$

The derivatives of $P_{\text {sys }}$ and $Q_{\text {sys }}$ depend upon the assumption of the output impedance of the DG. Since in this paper conventional droop equations (in which the output impedance of the DG is assumed to be inductive) are used, the partial derivatives of droop equations (19) and (20) are calculated as

$$
\begin{gathered}
\frac{\partial P_{s y s}}{\partial \delta_{k}}=0, \frac{\partial P_{\text {sys }}}{\partial\left|V_{k}\right|}=0, \frac{\partial P_{\text {sys }}}{\partial\left|V_{1}\right|}=0 \\
\frac{\partial Q_{s y s}}{\partial\left|V_{k}\right|}=\left\{\begin{array}{cc}
\frac{-1}{n_{q_{k}}} & \text { if bus } \mathrm{k} \text { is a droop bus } \\
0 & \text { otherwise }
\end{array}\right. \\
\frac{\partial Q_{s y s}}{\partial\left|V_{1}\right|}=\left\{\begin{array}{cc}
\frac{-1}{n_{q_{1}}} & \text { if bus } 1 \text { is a droop bus } \\
0 & \text { otherwise }
\end{array}\right. \\
\frac{\partial Q_{s y s}}{\partial \delta_{k}}=0, \frac{\partial Q_{s y s}}{\partial \omega}=0, \frac{\partial P_{s y s}}{\partial \omega}=\sum_{k=1}^{d} \frac{-1}{m_{p_{k}}}
\end{gathered}
$$

Once the Jacobian matrix is calculated, all the variables (voltage magnitudes, voltage angles and frequency) for the $(i+1)$ iteration are calculated using

$$
\boldsymbol{x}^{\prime i+1}=\boldsymbol{x}^{\prime i}+\boldsymbol{J}^{\prime-1} \cdot \boldsymbol{\Delta}^{\prime}
$$

Then, the error $\left(\Delta \boldsymbol{x}^{\prime}\right)$ is evaluated. If $\Delta \boldsymbol{x}^{\prime}$ satisfies the convergence criterion, line flows and voltages are evaluated. As mentioned earlier, the proposed method is also applicable in case of resistive or complex output impedance of DG. As a special case, the resistive and complex output impedance of DG is also studied. As explained earlier, the droops exchange their functions in case of resistive output impedance. Assuming the output impedance to be resistive, and by setting the references $P_{0}$ and $Q_{0}$ to zero in (7) and (8) [25], the active and reactive powers of a droop based bus can be expressed as

$$
\begin{gathered}
P_{G k}=\frac{1}{n_{q_{k}}}\left(\left|V_{o}\right|-\left|V_{k}\right|\right), \\
Q_{G_{k}}=\frac{1}{m_{p_{k}}}\left(\omega-\omega_{o}\right) .
\end{gathered}
$$

In this case, all the droop buses supply reactive power with the same angular frequency and $Q_{\text {sys }}$ becomes

$$
Q_{s y s}=\sum_{k=1}^{d} Q_{G_{k}}=\sum_{k=1}^{d} \frac{1}{m_{p_{k}}}\left(\omega-\omega_{o}\right)
$$

$P_{\text {sys }}$ in this case is expressed as

$$
P_{s y s}=\sum_{k=1}^{d} P_{G k}=\sum_{k=1}^{d} \frac{1}{n_{q_{k}}}\left(\left|V_{o}\right|-\left|V_{k}\right|\right)
$$

In this case, $Q_{\text {sys }}$ and $P_{\text {sys }}$ from (30) and (31) are used in (22) to calculate the modified mismatch matrix. Instead of taking derivatives of (19) and (20), the derivatives of the droop equations (30) and (31) are used to construct the modified Jacobian sub-matrices which are calculated as follows:

$$
\begin{aligned}
& \frac{\partial Q_{s y s}}{\partial\left|V_{k}\right|}=0, \frac{\partial Q_{s y s}}{\partial \delta_{k}}=0, \frac{\partial Q_{s y s}}{\partial\left|V_{1}\right|}=0 \\
& \frac{\partial P_{s y s}}{\partial \omega}=0, \frac{\partial P_{s y s}}{\partial \delta_{k}}=0, \frac{\partial Q_{s y s}}{\partial \omega}=\sum_{k=1}^{d} \frac{-1}{m_{p_{k}}} \\
& \frac{\partial P_{\text {sys }}}{\partial\left|V_{k}\right|}=\left\{\begin{array}{cc}
\frac{-1}{n_{q_{k}}} & \text { if bus } \mathrm{k} \text { is a droop bus } \\
0 & \text { otherwise }
\end{array}\right. \\
& \frac{\partial P_{\text {sys }}}{\partial\left|V_{1}\right|}=\left\{\begin{array}{rc}
\frac{-1}{n_{q_{1}}} & \text { if bus } 1 \text { is a droop bus } \\
0 & \text { otherwise }
\end{array}\right.
\end{aligned}
$$

Once the modified Jacobian is calculated, the frequency and the voltages are calculated using (27).

In case of complex output impedance of DGs, (9) and (10) can be modified to calculate the active and reactive power generation of a droop bus as follows:

$$
\begin{aligned}
& P_{G k}=\frac{1}{2}\left[\frac{1}{m_{p_{k}}}\left(\omega_{o}-\omega\right)+\frac{1}{n_{q_{k}}}\left(\left|V_{o}\right|-\left|V_{k}\right|\right)\right] \\
& Q_{G_{k}}=\frac{1}{2}\left[\frac{1}{n_{q_{k}}}\left(\left|V_{o}\right|-\left|V_{k}\right|\right)-\frac{1}{m_{p_{k}}}\left(\omega_{o}-\omega\right)\right]
\end{aligned}
$$


If all the DGs in a microgrid operate in the droop mode, the sum of active and reactive power generation of all DGs is the total power generation of the microgrid which is given by

$$
\begin{aligned}
P_{\text {sys }} & =\sum_{k=1}^{d} \frac{1}{2}\left[\frac{1}{m_{p_{k}}}\left(\omega_{o}-\omega\right)+\frac{1}{n_{q_{k}}}\left(\left|V_{o}\right|-\left|V_{k}\right|\right)\right] \\
Q_{\text {sys }} & =\sum_{k=1}^{d} \frac{1}{2}\left[\frac{1}{n_{q_{k}}}\left(\left|V_{o}\right|-\left|V_{k}\right|\right)-\frac{1}{m_{p_{k}}}\left(\omega_{o}-\omega\right)\right]
\end{aligned}
$$

Equations (32), (33), (34) and (35) are used to calculate the modified mismatch matrix $\left(\boldsymbol{\Delta}^{\prime}\right)$. To construct the modified Jacobian matrix $\left(\boldsymbol{J}^{\prime}\right)$, the derivatives of (34) and (35) are used which are calculated as

$$
\begin{aligned}
& \frac{\partial Q_{s y s}}{\partial \delta_{k}}=0, \quad \frac{\partial P_{s y s}}{\partial \delta_{k}}=0 \\
& \frac{\partial Q_{s y s}}{\partial\left|V_{k}\right|}=\left\{\begin{array}{cl}
\frac{-1}{2 n_{q_{k}}} & \text { if bus } \mathrm{k} \text { is a droop bus } \\
0 & \text { otherwise }
\end{array}\right. \\
& \frac{\partial Q_{\text {sys }}}{\partial\left|V_{1}\right|}=\left\{\begin{array}{cl}
\frac{-1}{2 n_{q_{1}}} & \text { if bus } 1 \text { is a droop bus } \\
0 & \text { otherwise }
\end{array}\right. \\
& \frac{\partial P_{\text {sys }}}{\partial\left|V_{k}\right|}=\left\{\begin{array}{cl}
\frac{-1}{2 n_{q_{k}}} & \text { if bus } \mathrm{k} \text { is a droop bus } \\
0 & \text { otherwise }
\end{array}\right. \\
& \frac{\partial P_{s y s}}{\partial\left|V_{1}\right|}=\left\{\begin{array}{cl}
\frac{-1}{2 n_{q_{1}}} & \text { if bus } 1 \text { is a droop bus } \\
0 & \text { otherwise }
\end{array}\right. \\
& \frac{\partial P_{\text {sys }}}{\partial \omega}=\sum_{k=1}^{d} \frac{-1}{2 m_{p_{k}}}, \frac{\partial Q_{s y s}}{\partial \omega}=\sum_{k=1}^{d} \frac{1}{2 m_{p_{k}}}
\end{aligned}
$$

Once the Jacobian matrix is calculated, all the variables for the $(i+1)$ iteration are calculated using (27) and if $\Delta \boldsymbol{x}^{\prime}$ satisfies the convergence criterion, line flows and voltages are evaluated.

\section{Validation of the Proposed Method}

To validate the proposed power flow approach, the results from the MNR power flow method are compared with the steady state values obtained from a detailed time domain model. The method is applied to two test systems (a 6-bus test system and a 38-bus test system). The parameters for both test systems can be found in [5] and [31]. Five cases have been studied. The first four case studies are presented for the 6-bus test system which is shown in Fig. 2. In case 1 , the three DGs are identical and operate using $P-\omega$ and $Q-V$ droop functions. In Case 2, resistive output impedance of DGs is assumed where the three identical DGs operate using $P-V$ and $Q-\omega$ droops. Case 3 considers the complex output

\begin{tabular}{|c|c|c|c|c|}
\hline \multirow{3}{*}{ Bus } & \multicolumn{4}{|c|}{ Voltage } \\
\hline & \multicolumn{2}{|c|}{ Magnitude (p.u.) } & \multicolumn{2}{|c|}{ Angle (deg) } \\
\hline & MNR & PSCAD & MNR & PSCAD \\
\hline 1 & 0.9566 & 0.9565 & 0 & 0 \\
\hline 2 & 0.9704 & 0.9703 & -0.5597 & -0.5604 \\
\hline 3 & 0.9611 & 0.9610 & -2.8714 & -2.8719 \\
\hline 4 & 0.9861 & 0.9861 & -0.0870 & -0.0878 \\
\hline 5 & 0.9893 & 0.9893 & -0.4769 & -0.4778 \\
\hline 6 & 0.9670 & 0.9670 & -3.0693 & -3.0702 \\
\hline \multicolumn{5}{|c|}{ System Frequency (p.u.) } \\
\hline \multicolumn{3}{|c|}{ MNR } & \multicolumn{2}{|c|}{ PSCAD } \\
\hline \multicolumn{3}{|c|}{0.99903} & \multicolumn{2}{|c|}{0.99903} \\
\hline \multicolumn{3}{|c|}{ Maximum Voltage Error } & Magnitude & Angle \\
\hline \multicolumn{3}{|c|}{ Absolute } & 0.0001 & 0.0009 \\
\hline \multicolumn{3}{|c|}{ Relative $(\%)$} & 0.0104 & 0.91 \\
\hline
\end{tabular}
impedance of DGs in which there exists a coupling between active and reactive power generation of DGs. In this case, the three DGs operate using $P-V-\omega$ and $Q-V-\omega$

\begin{tabular}{|c|c|c|c|c|}
\hline \multirow{3}{*}{ Bus } & \multicolumn{4}{|c|}{ Voltage } \\
\hline & \multicolumn{2}{|c|}{ Magnitude (p.u.) } & \multicolumn{2}{|c|}{ Angle (deg) } \\
\hline & MNR & PSCAD & MNR & PSCAD \\
\hline 1 & 0.9601 & 0.9600 & 0 & 0 \\
\hline 2 & 0.9726 & 0.9725 & -0.5222 & 0.5213 \\
\hline 3 & 0.9639 & 0.9639 & -2.6708 & -2.6706 \\
\hline 4 & 0.9873 & 0.9872 & -0.0727 & -0.0739 \\
\hline 5 & 0.9901 & 0.9901 & -0.4453 & -0.4458 \\
\hline 6 & 0.9694 & 0.9694 & -2.8535 & -2.8538 \\
\hline \multicolumn{5}{|c|}{ System Frequency (p.u.) } \\
\hline \multicolumn{3}{|c|}{ MNR } & \multicolumn{2}{|c|}{ PSCAD } \\
\hline \multicolumn{3}{|c|}{0.99911} & \multicolumn{2}{|c|}{0.99911} \\
\hline \multicolumn{3}{|c|}{ Maximum Voltage Error } & Magnitude & Angle \\
\hline \multicolumn{3}{|c|}{ Absolute } & 0.0001 & 0.0009 \\
\hline \multicolumn{3}{|c|}{ Relative $(\%)$} & 0.0104 & 1.62 \\
\hline
\end{tabular}
droops. In addition, for the three cases, two different load dependencies (constant power and constant impedance) have
TABLE I

VALidATION RESUlts FOR CASE $1(\alpha=0, \beta=0)$

TABLE II

VAlidation Results FOR CASE $1(\alpha=2, \beta=2)$

also been taken into consideration. The results for case 1 are presented in Table I and Table II, and the results for case 2 are presented in Table III and Table IV. The results for case 3 are shown in Table $\mathrm{V}$ and Table VI. As can be observed from these tables, the simulation results of the MNR power flow method closely match the results obtained from the time domain model in PSCAD/EMTDC. In case 4, the power flow method is validated for an islanded microgrid with a mix of DGs operation. Two out of the three DGs (DG2 and DG3) in the microgrid operate in $P-\omega$ and $Q-V$ droop mode and one DG (DG1) operates as a PV bus. The PV bus supplies a fixed active power of 4.0 p.u. while regulating its voltage to 1.002 p.u. Results for case 4 are presented in Table VII.

In case 5 , the proposed power flow method is tested on the 38 bus system which is shown in Fig. 3. The test system has five DGs placed on buses 34, 35, 36, 37 and 38. The DGs operate in the $P-\omega$ and $Q-V$ droop mode. Further, in this case, different droop gains have been used for the DGs and a limit on reactive power $\left(Q_{\max }\right)$ has been set. The droops gains, nominal voltage and reactive power limits for 
TABLE III

VAlidation Results For CASE $2(\alpha=0, \beta=0)$

\begin{tabular}{|c|c|c|c|c|}
\hline \multirow{3}{*}{ Bus } & \multicolumn{4}{|c|}{ Voltage } \\
\hline & \multicolumn{2}{|c|}{ Magnitude (p.u.) } & \multicolumn{2}{|c|}{ Angle (deg) } \\
\hline & MNR & PSCAD & MNR & PSCAD \\
\hline 1 & 0.9527 & 0.9525 & 0 & 0 \\
\hline 2 & 0.9727 & 0.9726 & -0.0320 & -0.0316 \\
\hline 3 & 0.9437 & 0.9436 & 0.4744 & 0.4766 \\
\hline 4 & 0.9786 & 0.9786 & -0.5100 & -0.5091 \\
\hline 5 & 0.9860 & 0.9860 & -0.4579 & -0.4571 \\
\hline 6 & 0.9520 & 0.9519 & 0.4666 & 0.4678 \\
\hline \multicolumn{5}{|c|}{ System Frequency (p.u.) } \\
\hline \multicolumn{3}{|c|}{ MNR } & \multicolumn{2}{|c|}{ PSCAD } \\
\hline \multicolumn{3}{|c|}{1.00065} & \multicolumn{2}{|c|}{1.00065} \\
\hline \multicolumn{3}{|c|}{ Maximum Voltage Error } & Magnitude & Angle \\
\hline \multicolumn{3}{|c|}{ Absolute } & 0.0002 & 0.0022 \\
\hline \multicolumn{3}{|c|}{ Relative (\%) } & 0.021 & 1.26 \\
\hline
\end{tabular}

TABLE IV

VALidation Results For CASE $2(\alpha=2, \beta=2)$

\begin{tabular}{|c|c|c|c|c|}
\hline \multirow{3}{*}{ Bus } & \multicolumn{4}{|c|}{ Voltage } \\
\hline & \multicolumn{2}{|c|}{ Magnitude (p.u.) } & \multicolumn{2}{|c|}{ Angle (deg) } \\
\hline & MNR & PSCAD & MNR & PSCAD \\
\hline 1 & 0.9569 & 0.9567 & 0 & 0 \\
\hline 2 & 0.9752 & 0.9751 & -0.0423 & -0.0417 \\
\hline 3 & 0.9494 & 0.9493 & 0.4065 & 0.4078 \\
\hline 4 & 0.9805 & 0.9804 & -0.4550 & -0.4537 \\
\hline 5 & 0.9872 & 0.9872 & -0.4244 & -0.4238 \\
\hline 6 & 0.9568 & 0.9568 & 0.3974 & 0.3989 \\
\hline \multicolumn{5}{|c|}{ System Frequency (p.u.) } \\
\hline \multicolumn{3}{|c|}{ MNR } & \multicolumn{2}{|c|}{ PSCAD } \\
\hline \multicolumn{3}{|c|}{1.00059} & \multicolumn{2}{|c|}{1.00059} \\
\hline \multicolumn{3}{|c|}{ Maximum Voltage Error } & Magnitude & Angle \\
\hline \multicolumn{3}{|c|}{ Absolute } & 0.0002 & 0.0015 \\
\hline \multicolumn{3}{|c|}{ Relative (\%) } & 0.0209 & 1.43 \\
\hline
\end{tabular}

all DGs are given in Table $\mathrm{X}$ in Appendix A. Additionally, a different load dependency for the loads at the different buses has been utilized based on classifying the loads as residential (R), commercial (C) or industrial (I) [31]. Table VIII presents a comparison of the results of the MNR method and PSCAD. Note that the reactive power of DG5 (at bus 38) exceeds the limit, and hence has been set to its maximum value. The system frequency converges to 0.99813 p.u. The convergence is improved by applying an acceleration factor (shown in Appendix A) separately to the voltage magnitude and the voltage angle. The convergence in all cases is less than 10 iterations for a tolerance of $10^{-5}$. The maximum voltage magnitude, phase angle and system frequency error in all cases is less than $0.0002,0.0085$ and 0.00001 , respectively.

The simulation results, presented in this paper, closely match the results presented using the Newton Trust region method proposed in [5] and the results obtained using PSCAD. In comparison to [5], the newton trust region involves a constrained minimization of a quadratic function subject to a nonlinear constraint. As mentioned in [32], the solution of
TABLE V

VAlidation Results for CASE $3(\alpha=0, \beta=0)$

\begin{tabular}{|c|c|c|c|c|}
\hline \multirow{3}{*}{ Bus } & \multicolumn{4}{|c|}{ Voltage } \\
\hline & \multicolumn{2}{|c|}{ Magnitude (p.u.) } & \multicolumn{2}{|c|}{ Angle (deg) } \\
\hline & MNR & PSCAD & MNR & PSCAD \\
\hline 1 & 0.9300 & 0.9299 & 0 & 0 \\
\hline 2 & 0.9470 & 0.9469 & -0.3410 & -0.3407 \\
\hline 3 & 0.9296 & 0.9295 & -1.5781 & -1.5763 \\
\hline 4 & 0.9588 & 0.9587 & -0.2896 & -0.2894 \\
\hline 5 & 0.9641 & 0.9640 & -0.4510 & -0.4505 \\
\hline 6 & 0.9367 & 0.9366 & -1.7070 & -1.7052 \\
\hline \multicolumn{5}{|c|}{ System Frequency (p.u.) } \\
\hline \multicolumn{3}{|c|}{ MNR } & \multicolumn{2}{|c|}{ PSCAD } \\
\hline \multicolumn{3}{|c|}{0.999698} & \multicolumn{2}{|c|}{0.999698} \\
\hline \multicolumn{3}{|c|}{ Maximum Voltage Error } & Magnitude & Angle \\
\hline \multicolumn{3}{|c|}{ Absolute } & 0.0001 & 0.0018 \\
\hline \multicolumn{3}{|c|}{ Relative (\%) } & 0.0106 & 0.114 \\
\hline
\end{tabular}

TABLE VI

VALIDATION RESUltS FOR REDCASE $3(\alpha=2, \beta=2)$

\begin{tabular}{|c|c|c|c|c|}
\hline \multirow{3}{*}{ Bus } & \multicolumn{4}{|c|}{ Voltage } \\
\hline & \multicolumn{2}{|c|}{ Magnitude (p.u.) } & \multicolumn{2}{|c|}{ Angle (deg) } \\
\hline & MNR & PSCAD & MNR & PSCAD \\
\hline 1 & 0.9387 & 0.9386 & 0 & 0 \\
\hline 2 & 0.9535 & 0.9534 & -0.2961 & -0.2963 \\
\hline 3 & 0.9383 & 0.9382 & -1.3713 & -1.371 \\
\hline 4 & 0.9638 & 0.9637 & -0.2507 & -0.2515 \\
\hline 5 & 0.9684 & 0.9684 & -0.3919 & -0.3927 \\
\hline 6 & 0.9444 & 0.9443 & -1.4825 & -1.4823 \\
\hline \multicolumn{5}{|c|}{ System Frequency (p.u.) } \\
\hline \multicolumn{3}{|c|}{ MNR } & \multicolumn{2}{|c|}{ PSCAD } \\
\hline \multicolumn{3}{|c|}{0.999735} & \multicolumn{2}{|c|}{0.999735} \\
\hline \multicolumn{3}{|c|}{ Maximum Voltage Error } & Magnitude & Angle \\
\hline \multicolumn{3}{|c|}{ Absolute } & 0.0001 & 0.0008 \\
\hline \multicolumn{3}{|c|}{ Relative (\%) } & 0.0106 & 0.318 \\
\hline
\end{tabular}

TABLE VII

VALIDATION RESULTS FOR CASE $4(\alpha=2, \beta=2)$

\begin{tabular}{|c|c|c|c|c|}
\hline \multirow{3}{*}{ Bus } & \multicolumn{4}{|c|}{ Voltage } \\
\hline & \multicolumn{2}{|c|}{ Magnitude (p.u.) } & \multicolumn{2}{|c|}{ Angle (deg) } \\
\hline & $\overline{M N R}$ & PSCAD & MNR & PSCAD \\
\hline 1 & 0.9702 & 0.9704 & 0 & 0 \\
\hline 2 & 0.9780 & 0.9781 & -0.1682 & -0.1684 \\
\hline 3 & 0.9656 & 0.9656 & -2.4125 & -2.4139 \\
\hline 4 & 1.0020 & 1.0020 & -0.2974 & -0.2964 \\
\hline 5 & 0.9938 & 0.9939 & 0.0136 & 0.0134 \\
\hline 6 & 0.9708 & 0.9708 & -2.5864 & -2.5885 \\
\hline \multicolumn{5}{|c|}{ System Frequency (p.u.) } \\
\hline \multicolumn{3}{|c|}{ MNR } & \multicolumn{2}{|c|}{ PSCAD } \\
\hline \multicolumn{3}{|c|}{0.99915} & \multicolumn{2}{|c|}{0.99915} \\
\hline \multicolumn{3}{|c|}{ Maximum Voltage Error } & Magnitude & Angle \\
\hline \multicolumn{3}{|c|}{ Absolute } & 0.0002 & 0.0021 \\
\hline \multicolumn{3}{|c|}{ Relative (\%) } & 0.0206 & 1.492 \\
\hline
\end{tabular}

such problem is not trivial and the algorithmic complexity is much higher when compared to other methods. On the 
TABLE VIII

VALidation Results For CASE 5 (38-Bus Test System)

\begin{tabular}{|c|c|c|c|c|c|c|c|c|}
\hline \multirow[t]{2}{*}{ Bus } & \multicolumn{2}{|c|}{ Voltage Magnitude (p.u.) } & \multicolumn{2}{|c|}{ Voltage Angle (deg) } & \multicolumn{2}{|c|}{ Load $\left(P_{L}\right)$} & \multicolumn{2}{|c|}{ Load $\left(Q_{L}\right)$} \\
\hline & MNR & PSCAD & MNR & PSCAD & MNR & PSCAD & MNR & PSCAD \\
\hline 1 & 0.9802 & 0.9802 & 0 & 0 & - & - & - & - \\
\hline 2 & 0.9802 & 0.9802 & 0 & 0 & -0.0980 & -0.0982 & -0.0554 & -0.0553 \\
\hline 3 & 0.9790 & 0.9790 & -0.0275 & -0.0279 & -0.0895 & -0.0897 & -0.0353 & -0.0351 \\
\hline 4 & 0.9787 & 0.9787 & -0.0585 & -0.0591 & -0.1159 & -0.1162 & -0.0745 & -0.0744 \\
\hline 5 & 0.9787 & 0.9787 & -0.0930 & -0.0937 & -0.0587 & -0.0588 & -0.0275 & -0.0275 \\
\hline 6 & 0.9796 & 0.9796 & -0.1699 & -0.1707 & -0.0597 & -0.0598 & -0.0177 & -0.0177 \\
\hline 7 & 0.9825 & 0.9825 & -0.2940 & -0.2954 & -0.1944 & -0.1948 & -0.0943 & -0.0942 \\
\hline 8 & 0.9834 & 0.9834 & -0.5453 & -0.5469 & -0.1946 & -0.1951 & -0.0946 & -0.0945 \\
\hline 9 & 0.9834 & 0.9834 & -0.7487 & -0.7500 & -0.0597 & -0.0598 & -0.0181 & -0.0181 \\
\hline 10 & 0.9838 & 0.9838 & -0.9447 & -0.9471 & -0.0584 & -0.0585 & -0.019 & -0.0189 \\
\hline 11 & 0.9838 & 0.9838 & -0.9762 & -0.9786 & -0.0438 & -0.0439 & -0.0284 & -0.0284 \\
\hline 12 & 0.9839 & 0.9839 & -1.0380 & -1.0404 & -0.0590 & -0.0591 & -0.0328 & -0.0329 \\
\hline 13 & 0.9784 & 0.9784 & -1.1254 & -1.1284 & -0.0579 & -0.058 & -0.0326 & -0.0326 \\
\hline 14 & 0.9764 & 0.9764 & -1.1961 & -1.2001 & -0.1172 & -0.1174 & -0.0728 & -0.0729 \\
\hline 15 & 0.9752 & 0.9751 & -1.2307 & -1.2349 & -0.0577 & -0.0577 & -0.0092 & -0.0092 \\
\hline 16 & 0.9739 & 0.9739 & -1.2534 & -1.2579 & -0.0596 & -0.0597 & -0.0171 & -0.0171 \\
\hline 17 & 0.9722 & 0.9721 & -1.3230 & -1.3280 & -0.0574 & -0.0575 & -0.0182 & -0.0182 \\
\hline 18 & 0.9716 & 0.9715 & -1.3330 & -1.3380 & -0.0894 & -0.0895 & -0.0337 & -0.0336 \\
\hline 19 & 0.9807 & 0.9808 & 0.0212 & 0.02160 & -0.0882 & -0.0884 & -0.037 & -0.0367 \\
\hline 20 & 0.9872 & 0.9872 & 0.2245 & 0.2282 & -0.0881 & -0.0882 & -0.0383 & -0.0383 \\
\hline 21 & 0.9893 & 0.9894 & 0.3112 & 0.3160 & -0.0897 & -0.0898 & -0.0376 & -0.0375 \\
\hline 22 & 0.9939 & 0.994 & 0.5066 & 0.5135 & -0.0893 & -0.0895 & -0.0391 & -0.039 \\
\hline 23 & 0.9785 & 0.9786 & -0.0149 & -0.0155 & -0.0869 & -0.0871 & -0.0465 & -0.0464 \\
\hline 24 & 0.9783 & 0.9783 & 0.0149 & 0.0141 & -0.4055 & -0.4064 & -0.1859 & -0.1855 \\
\hline 25 & 0.9811 & 0.9812 & 0.0880 & 0.0875 & -0.4073 & -0.4082 & -0.1878 & -0.1875 \\
\hline 26 & 0.9796 & 0.9796 & -0.1136 & -0.1142 & -0.0581 & -0.05817 & -0.0234 & -0.0233 \\
\hline 27 & 0.9798 & 0.9798 & -0.0342 & -0.0345 & -0.0597 & -0.05981 & -0.0222 & -0.0221 \\
\hline 28 & 0.9796 & 0.9796 & 0.3296 & 0.3304 & -0.0581 & -0.05817 & -0.0187 & -0.0187 \\
\hline 29 & 0.9799 & 0.9799 & 0.6138 & 0.6158 & -0.1162 & -0.1164 & -0.0654 & -0.0653 \\
\hline 30 & 0.9767 & 0.9767 & 0.6969 & 0.6985 & -0.1926 & -0.1932 & -0.5549 & -0.5535 \\
\hline 31 & 0.9730 & 0.9730 & 0.6191 & 0.6198 & -0.146 & -0.1463 & -0.0628 & -0.0626 \\
\hline 32 & 0.9722 & 0.9722 & 0.5982 & 0.5987 & -0.2042 & -0.2047 & -0.0894 & -0.0892 \\
\hline \multirow[t]{2}{*}{33} & 0.9720 & 0.9719 & 0.5915 & 0.5919 & -0.0574 & -0.0575 & -0.0364 & -0.0363 \\
\hline & & & & & \multicolumn{2}{|c|}{ Generation $\left(P_{G}\right)$} & \multicolumn{2}{|c|}{$\operatorname{Generation}\left(Q_{G}\right)$} \\
\hline 34 & 0.9964 & 0.9965 & -0.7724 & -0.7726 & 0.3670 & 0.3678 & 0.6777 & 0.6764 \\
\hline 35 & 0.9993 & 0.9994 & 1.2862 & 1.2904 & 1.2465 & 1.2490 & 0.3203 & 0.3181 \\
\hline 36 & 0.9971 & 0.9971 & -1.2054 & -1.2067 & 0.4155 & 0.4165 & 0.6446 & 0.6435 \\
\hline 37 & 0.9973 & 0.9974 & 0.6195 & 0.6178 & 0.831 & 0.833 & 0.2554 & 0.2527 \\
\hline \multirow[t]{2}{*}{38} & 0.9847 & 0.9848 & 0.1856 & 0.1858 & 0.831 & 0.833 & 0.3000 & 0.3000 \\
\hline & & $\mathbf{P}_{\mathbf{G}}$ & $\mathbf{Q}_{\mathbf{G}}$ & $\mathbf{P}_{\mathbf{L}}$ & $\mathbf{Q}_{\mathbf{L}}$ & $\mathbf{P}_{\text {Loss }}$ & $\mathbf{Q}_{\text {Loss }}$ & \\
\hline Total & & 3.692 & 2.195 & 3.618 & 2.126 & 0.0732 & 0.0682 & \\
\hline \multicolumn{3}{|c|}{ Maximum Voltage Error } & & & \multicolumn{2}{|c|}{ Magnitude } & \multicolumn{2}{|c|}{ Angle } \\
\hline \multicolumn{3}{|c|}{ Absolute } & & & \multicolumn{2}{|c|}{0.0001} & \multicolumn{2}{|c|}{0.0083} \\
\hline \multicolumn{3}{|c|}{ Relative $(\%)$} & & & \multicolumn{2}{|c|}{0.0102} & \multicolumn{2}{|c|}{3.87} \\
\hline
\end{tabular}

other hand, distribution power flow methods, such as the BFS method, are fast and simple. The BFS method relies on power or current summations, and is basically a direct application of Kirchhoff's Current Law (KCL) and Kirchhoff's Voltage Law (KVL). However, as mentioned earlier, its application is limited to only radial and weakly meshed systems. Furthermore, the BFS method is applicable to grid connected systems and cannot be applied directly to droop based microgrids. Table IX provides a comparison between several power flow methods in terms of number of iterations, applicability (to grid connected microgrid (GCM) and islanded microgrid (IM)) and computational time. As can be seen, the BFS method is very efficient for grid connected radial distribution systems when compared to the proposed MNR method. On the contrary, the MNR method is applicable to islanded systems equipped with droops. The computation time of the MNR method in comparison to the NR method is higher which can be attributed to the inclusion of the frequency as a variable in the Jacobian matrix. For a small-scale islanded microgrid, the difference in the number of iterations or speed between the MNR and other power flow methods is smaller when compared to the results obtained for larger micro-grid systems. The method proposed 


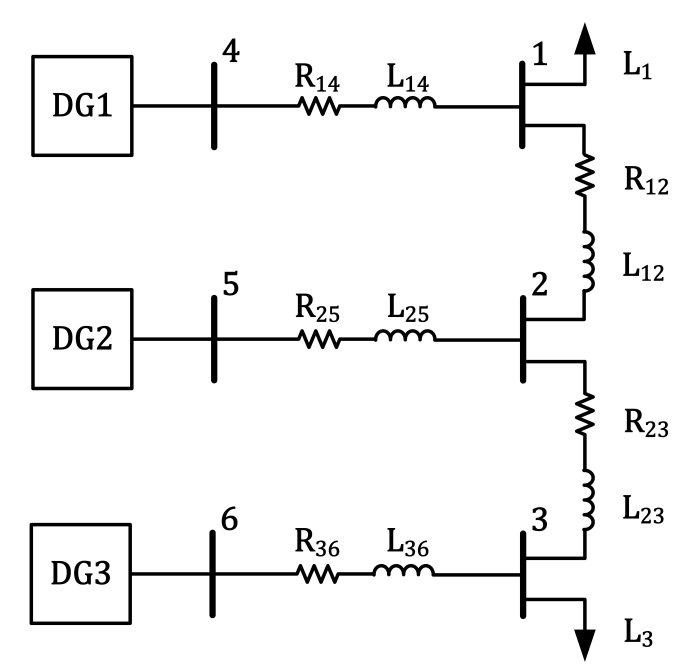

Fig. 2. The 6-bus test system

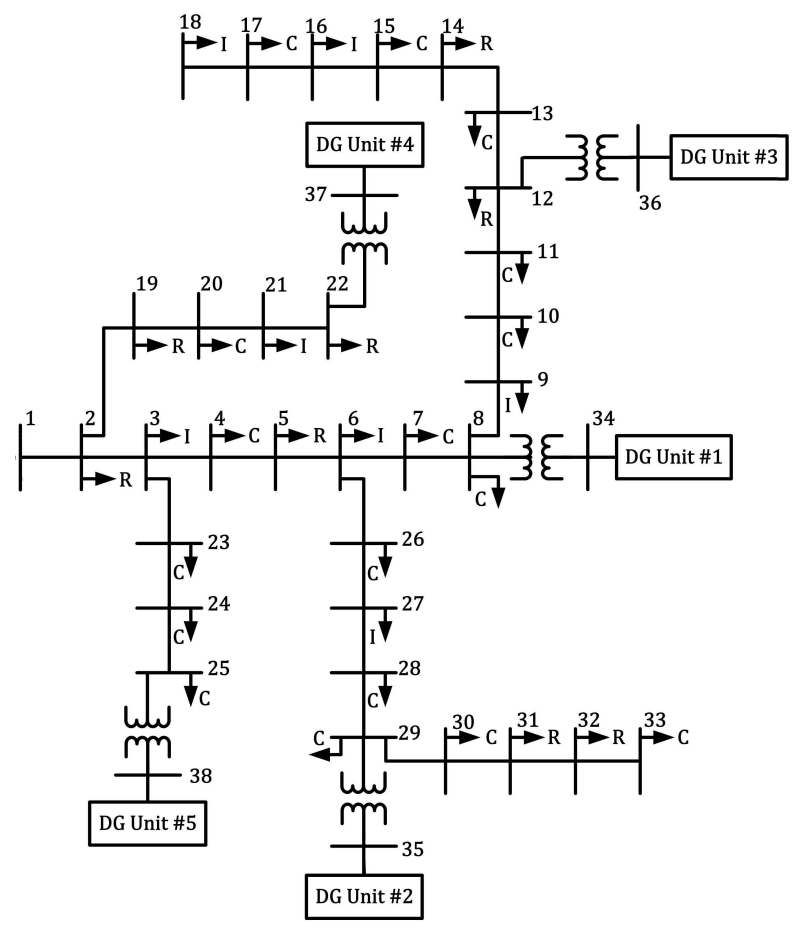

Fig. 3. The 38-bus test system

in this paper is simple, does not involve optimization and relies on the calculation of a few additional Jacobian sub-matrices while maintaining adequate accuracy levels.

TABLE IX

Computation Time Considering Various Power Flow Methods

\begin{tabular}{|c|c|c|c|c|c|c|}
\hline \multirow{3}{*}{$\begin{array}{c}\text { No. } \\
\text { of } \\
\text { Buses }\end{array}$} & \multicolumn{6}{|c|}{ Computational Time (seconds)/No. of iterations } \\
\hline & \multicolumn{2}{|c|}{ NR Method } & \multicolumn{2}{|c|}{ BFS Method } & \multicolumn{2}{|c|}{ MNR Method } \\
\hline & $\mathrm{GCM}$ & IM & GCM & IM & GCM & IM \\
\hline 6 & $0.022 / 4$ & $\begin{array}{l}\text { Not } \\
\text { Applicable }\end{array}$ & $0.020 / 4$ & $\begin{array}{l}\text { Not } \\
\text { Applicable }\end{array}$ & $\begin{array}{l}\text { Not } \\
\text { Applicable }\end{array}$ & $0.040 / 8$ \\
\hline 38 & $0.150 / 4$ & $\begin{array}{l}\text { Not } \\
\text { Applicable }\end{array}$ & $0.055 / 4$ & $\begin{array}{l}\text { Not } \\
\text { Applicable }\end{array}$ & $\begin{array}{l}\text { Not } \\
\text { Applicable }\end{array}$ & $0.450 / 8$ \\
\hline
\end{tabular}

\section{CONClusion}

In this paper, a novel approach is used to solve the power flow for islanded microgrid using a Modified Newton Raphson (MNR) method. The proposed method takes into consideration the absence of slack bus in an islanded microgrid and formulates the generator bus as a droop bus. The method has been tested on two test systems under different load dependency conditions and also under different droop characteristics. A good agreement of the results indicates the accuracy of the proposed method. The proposed method is very simple because it relies on the conventional NR method but with simple yet effective modifications, and hence can be easily integrated to any power system software and can be a useful tool for utility operators planning the operation of microgrids.

\section{APPENDIX A}

Acceleration Factor:

$$
\boldsymbol{x}^{\prime i+1}=\boldsymbol{x}^{i}+\operatorname{acc}\left(\boldsymbol{x}^{\prime i+1}-\boldsymbol{x}^{i}\right)
$$

where $a c c$ is the acceleration factor and its value is between 0 and 2. Using a different value of $a c c$ for the voltage magnitude and the voltage angle results in faster convergence.

The DG parameters for the 38-bus test system, shown in Fig. 3 are given in Table X.

TABLE $X$

DG Locations, STATIC Droop Gains, S ystem Nominal VALUES AND Q LIMITS FOR THE 38-BUS TEST SYSTEM

\begin{tabular}{ccccccc}
\hline DG & Location & $m_{p}$ & $n_{q}$ & $\omega_{o}$ & $V_{o}$ & $Q_{\max }$ \\
\hline 1 & 34 & $5.102 \times 10^{-3}$ & 0.02 & 1 & 1.01 & 0.9 \\
2 & 35 & $1.502 \times 10^{-3}$ & 0.03333 & 1 & 1.01 & 0.6 \\
3 & 36 & $4.506 \times 10^{-3}$ & 0.02 & 1 & 1.01 & 0.9 \\
4 & 37 & $2.253 \times 10^{-3}$ & 0.05 & 1 & 1.01 & 0.3 \\
5 & 38 & $2.253 \times 10^{-3}$ & 0.05 & 1 & 1.01 & 0.3 \\
\hline
\end{tabular}

\section{APPENDIX B}

The mismatch matrix for the conventional Newton Raphson method is given by [3]

$$
\boldsymbol{\Delta}=\left[\begin{array}{ll}
\boldsymbol{P}^{T}-\boldsymbol{P}_{c}^{T} & \boldsymbol{Q}^{T}-\boldsymbol{Q}_{c}^{T}
\end{array}\right]^{T},
$$

where

$$
\boldsymbol{P}=\left[\begin{array}{c}
P_{2} \\
\vdots \\
P_{N}
\end{array}\right], \boldsymbol{P}_{c}=\left[\begin{array}{c}
P_{c 2} \\
\vdots \\
P_{c N}
\end{array}\right], \boldsymbol{Q}=\left[\begin{array}{c}
Q_{2} \\
\vdots \\
Q_{N}
\end{array}\right], \boldsymbol{Q}_{c}=\left[\begin{array}{c}
Q_{c 2} \\
\vdots \\
Q_{c N}
\end{array}\right]
$$

where $P_{k}$ and $Q_{k}$ are the scheduled real and reactive power at bus $k$, respectively. $P_{c k}$ and $Q_{c k}$ are the calculated real and reactive power at bus $k$, respectively. The Jacobian submatrices $\left(\boldsymbol{J}_{11}, \boldsymbol{J}_{12}, \boldsymbol{J}_{21}\right.$ and $\left.\boldsymbol{J}_{22}\right)$ for the conventional Newton Raphson method are given by [3] 
$\left\{\begin{array}{c}\boldsymbol{J}_{11}=\left[\begin{array}{ccc}\frac{\partial P_{c 2}}{\partial \delta_{2}} & \cdots & \frac{\partial P_{c 2}}{\partial \delta_{N}} \\ \vdots & \ddots & \vdots \\ \frac{\partial P_{c N}}{\partial \delta_{2}} & \cdots & \frac{\partial P_{c_{N}}}{\partial \delta_{N}}\end{array}\right], \boldsymbol{J}_{12}=\left[\begin{array}{ccc}\frac{\partial P_{c 2}}{\partial\left|V_{2}\right|} & \cdots & \frac{\partial P_{c 2}}{\partial\left|V_{N}\right|} \\ \vdots & \ddots & \vdots \\ \frac{\partial P_{c N}}{\partial \mid V_{2}} & \cdots & \frac{\partial P_{c N}}{\partial \mid V_{N}}\end{array}\right] \\ \boldsymbol{J}_{21}=\left[\begin{array}{cccc}\frac{\partial Q_{c 2}}{\partial \delta_{2}} & \cdots & \frac{\partial Q_{c 2}}{\partial \delta_{N}} \\ \vdots & \ddots & \vdots \\ \frac{\partial Q_{c_{N}}}{\partial \delta_{2}} & \cdots & \frac{\partial Q_{c_{N}}}{\partial \delta_{N}}\end{array}\right], \boldsymbol{J}_{22}=\left[\begin{array}{ccc}\frac{\partial Q_{c 2}}{\partial\left|V_{2}\right|} & \cdots & \frac{\partial Q_{c 2}}{\partial\left|V_{N}\right|} \\ \vdots & \ddots & \vdots \\ \frac{\partial Q_{c N}}{\partial\left|V_{2}\right|} & \cdots & \frac{\partial Q_{c N}}{\partial\left|V_{N}\right|}\end{array}\right]\end{array}\right.$

\section{REFERENCES}

[1] P. S. Bhowmik, S. Bose, D. V. Rajan, and S. Deb, "Power flow analysis of power system using power perturbation method," in Power Engineering and Automation Conference (PEAM), 2011 IEEE, vol. 3, Sept 2011, pp. 380-384.

[2] H. Brown, G. Carter, H. Happ, and C. Person, "Z-matrix algorithms in load-flow programs," Power Apparatus Systems, IEEE Transactions on, vol. PAS-87, no. 3, pp. 807-814, March 1968.

[3] J. Grainger and W. Stevenson, Power System Analysis, ser. Electrical engineering series. McGraw-Hill, 1994.

[4] S. Jahdi, A. Etemadian, and L. L. Lai, "Dg modeling and compensation methods in distribution load flow analysis and voltage profile recovery," in Electrical Power Quality and Utilisation (EPQU), 2011 11th International Conference on, Oct 2011, pp. 1-6.

[5] M. Abdelaziz, H. Farag, E. El-Saadany, and Y.-R. Mohamed, "A novel and generalized three-phase power flow algorithm for islanded microgrids using a newton trust region method," Power Systems, IEEE Transactions on, vol. 28, no. 1, pp. 190-201, Feb 2013.

[6] A. Elrayyah, Y. Sozer, and M. Elbuluk, "A novel load-flow analysis for stable and optimized microgrid operation," Power Delivery, IEEE Transactions on, vol. 29, no. 4, pp. 1709-1717, Aug 2014.

[7] C. Li, S. Chaudhary, J. Vasquez, and J. Guerrero, "Power flow analysis algorithm for islanded lv microgrids including distributed generator units with droop control and virtual impedance loop," in Applied Power Electronics Conference and Exposition (APEC), 2014 Twenty-Ninth Annual IEEE, March 2014, pp. 3181-3185.

[8] M. Kamh and R. Iravani, "A sequence frame-based distributed slack bus model for energy management of active distribution networks," Smart Grid, IEEE Transactions on, vol. 3, no. 2, pp. 828-836, June 2012.

[9] D. Westermann and M. Kratz, "A real-time development platform for the next generation of power system control functions," Industrial Electronics, IEEE Transactions on, vol. 57, no. 4, pp. 1159-1166, April 2010.

[10] R. Majumder, G. Ledwich, A. Ghosh, S. Chakrabarti, and F. Zare, "Droop control of converter-interfaced microsources in rural distributed generation," Power Delivery, IEEE Transactions on, vol. 25, no. 4, pp. 2768-2778, Oct 2010.

[11] H. Nikkhajoei and R. Iravani, "Steady-state model and power flow analysis of electronically-coupled distributed resource units," Power Delivery, IEEE Transactions on, vol. 22, no. 1, pp. 721-728, Jan 2007.

[12] M. Kamh and R. Iravani, "Unbalanced model and power-flow analysis of microgrids and active distribution systems," Power Delivery, IEEE Transactions on, vol. 25, no. 4, pp. 2851-2858, Oct 2010.

[13] D. Shirmohammadi, H. Hong, A. Semlyen, and G. Luo, "A compensation-based power flow method for weakly meshed distribution and transmission networks," Power Systems, IEEE Transactions on, vol. 3, no. 2, pp. 753-762, May 1988.

[14] G. Luo and A. Semlyen, "Efficient load flow for large weakly meshed networks," Power Systems, IEEE Transactions on, vol. 5, no. 4, pp. 1309-1316, Nov 1990.

[15] G. Chang, S. Chu, and H. Wang, "An improved backward/forward sweep load flow algorithm for radial distribution systems," Power Systems, IEEE Transactions on, vol. 22, no. 2, pp. 882-884, May 2007.

[16] A. Augugliaro, L. Dusonchet, S. Favuzza, M. G. Ippolito, and E. R. Sanseverino, "A backward sweep method for power flow solution in distribution networks," International journal of electrical power \& energy systems, vol. 32, no. 4, pp. 271-280, 2010.

[17] "Load representation for dynamic performance analysis [of power systems]," Power Systems, IEEE Transactions on, vol. 8, no. 2, pp. 472-482, May 1993.
[18] R. Payasi, A. Singh, and D. Singh, "Effect of voltage step constraint and load models in optimal location and size of distributed generation," in Power, Energy and Control (ICPEC), 2013 International Conference on, Feb 2013, pp. 710-716.

[19] P. Kundur, N. Balu, and M. Lauby, Power System Stability and Control, ser. Discussion Paper Series. McGraw-Hill Education, 1994. [Online]. Available: http://books.google.ae/books?id=2cbvyf8Ly4AC

[20] T. Vandoorn, B. Meersman, L. Degroote, B. Renders, and L. Vandevelde, "A control strategy for islanded microgrids with dc-link voltage control," Power Delivery, IEEE Transactions on, vol. 26, no. 2, pp. 703-713, April 2011.

[21] F. Blaabjerg, R. Teodorescu, M. Liserre, and A. Timbus, "Overview of control and grid synchronization for distributed power generation systems," Industrial Electronics, IEEE Transactions on, vol. 53, no. 5, pp. 1398-1409, Oct 2006.

[22] E. Rokrok and M. Golshan, "Adaptive voltage droop scheme for voltage source converters in an islanded multibus microgrid," Generation, Transmission Distribution, IET, vol. 4, no. 5, pp. 562-578, May 2010.

[23] Y. A. R. I. Mohamed and E. El-Saadany, "Adaptive decentralized droop controller to preserve power sharing stability of paralleled inverters in distributed generation microgrids," Power Electronics, IEEE Transactions on, vol. 23, no. 6, pp. 2806-2816, Nov 2008.

[24] N. Pogaku, M. Prodanovic, and T. Green, "Modeling, analysis and testing of autonomous operation of an inverter-based microgrid," Power Electronics, IEEE Transactions on, vol. 22, no. 2, pp. 613-625, March 2007.

[25] J. Vasquez, J. Guerrero, M. Savaghebi, J. Eloy-Garcia, and R. Teodorescu, "Modeling, analysis, and design of stationary-reference-frame droop-controlled parallel three-phase voltage source inverters," Industrial Electronics, IEEE Transactions on, vol. 60, no. 4, pp. 1271-1280, April 2013.

[26] J. Guerrero, J. Matas, L. G. de Vicuna, M. Castilla, and J. Miret, "Decentralized control for parallel operation of distributed generation inverters using resistive output impedance," Industrial Electronics, IEEE Transactions on, vol. 54, no. 2, pp. 994-1004, April 2007.

[27] H. Bevrani and S. Shokoohi, "An intelligent droop control for simultaneous voltage and frequency regulation in islanded microgrids," Smart Grid, IEEE Transactions on, vol. 4, no. 3, pp. 1505-1513, Sept 2013.

[28] I. Committee et al., "Ieee standard for interconnecting distributed resources with electric power systems," IEEE Std. 1547-2003, pp. 1-28.

[29] W. Yao, M. Chen, J. Matas, J. Guerrero, and Z. ming Qian, "Design and analysis of the droop control method for parallel inverters considering the impact of the complex impedance on the power sharing," Industrial Electronics, IEEE Transactions on, vol. 58, no. 2, pp. 576-588, Feb 2011.

[30] K. De Brabandere, B. Bolsens, J. Van den Keybus, A. Woyte, J. Driesen, and R. Belmans, "A voltage and frequency droop control method for parallel inverters," Power Electronics, IEEE Transactions on, vol. 22, no. 4, pp. 1107-1115, July 2007.

[31] D. Singh, R. Misra, and D. Singh, "Effect of load models in distributed generation planning," Power Systems, IEEE Transactions on, vol. 22, no. 4, pp. 2204-2212, Nov 2007.

[32] F. V. Berghen, "Levenberg-marquardt algorithms vs trust region algorithms," IRIDIA, Université Libre de Bruxelles, 2004.

Faisal Mumtaz (S'14) received the B.Sc. degree in Electrical Power Engineering from the COMSATS Institute of Information Technology, Pakistan, in 2012 and the M.Sc. degree in Electrical Power Engineering from Masdar Institute of Science and Technology, Abu Dhabi, U.A.E., in 2015. He is currently pursuing his Ph.D. degree in Sustainable Energy from Hamad Bin Khalifa University, Doha, Qatar. His interests include distributed generation, demand side management, intelligent load shedding, stability and protection of microgrids.

M. H. Syed (S'13) received his B.E. degree in Electrical and Electronics Engineering from Osmania University, Hyderabad, India in 2011 and M.Sc. degree in Electrical Power Engineering from Masdar Institute of Science and Technology, Abu Dhabi, U.A.E., in 2013. He is currently with the Institute for Energy and Environment, Department of Electronic and Electrical Engineering, University of Strathclyde, where he is working towards his $\mathrm{Ph} . \mathrm{D}$. His research interests include power system stability, intelligent control, demand side management and electricity markets. 
Mohamed Al Hosani (S'10-M'13) received the B.Sc. degree in Electrical Engineering from the American University of Sharjah, U.A.E., in 2008 and the M.Sc. and the Ph.D. degrees in Electrical Engineering from the University of Central Florida, Orlando, U.S.A., in 2010 and 2013, respectively. He is currently an Assistant Professor with the Masdar Institute, Abu Dhabi, UAE. His current interests include anti-islanding algorithm, distributed generation protection and control, modeling and stability analysis of micro-grid and smart grid.

H. H. Zeineldin (M'06-SM'13) received the B.Sc. and M.Sc. degrees in electrical engineering from Cairo University, Cairo, Egypt, in 1999 and 2002, respectively, and the $\mathrm{Ph} . \mathrm{D}$. degree in electrical and computer engineering from the University of Waterloo, Waterloo, ON, Canada, in 2006. He was with Smith and Andersen Electrical Engineering, Inc., where he was involved with projects involving distribution system design, protection, and distributed generation. He was then a Visiting Professor at the Massachusetts Institute of Technology, Cambridge, MA, USA. He is with the Faculty of Engineering, Cairo University, and currently he is an Associate Professor with the Masdar Institute of Science and Technology, Masdar City, UAE. He is currently an Editor of the IEEE Transactions on Energy Conversion and IEEE Transactions on Smart Grids. His current interests include power system protection, distributed generation, and deregulation. 